\title{
Acquisition of leverpressing without experimenter assistance by rats on differential reinforcement of low-rate schedules
}

\author{
DANIEL C. LINWICK and LAURENCE MILLER \\ Western Washington University, Bellingham, Washington 98225
}

\begin{abstract}
Rats can acquire a continuously reinforced leverpressing response without experimenter assistance. In the present study, acquisition of responding on a more complex schedule, differential reinforcement of low rates (DRL), was examined. In a DRL schedule, successive responses are reinforced only if a minimum period of time has elapsed between successive responses. Twelve rats were placed directly on DRL 7.5, 15, and 30 sec. Eleven of 12 rats acquired leverpressing without experimenter assistance. Efficiency of responding was inversely related to DRL value.
\end{abstract}

Studies have shown rats to be capable of acquiring a leverpressing response for food without magazine training or experimenter assistance of any kind (Kopp, Bourland, Tarte, \& Vernon, 1976; Miller, 1976). Miller (1976) demonstrated that rats rapidly acquire leverpressing. In this study each leverpress produced a pellet (continuous reinforcement, CRF). Six of 10 animals acquired leverpressing within about $15-60 \mathrm{~min}$ after being placed in the chamber.

In the present study, acquisition of responding maintained by differential reinforcement of low rates (DRL) without prior magazine training or experimenter assistance was examined. In a DRL schedule successive responses are reinforced only if a minimum period of time has elapsed between successive responses. For example, in a DRL 15-sec schedule, successive responses are reinforced only if at least $15 \mathrm{sec}$ have elapsed between each response. Interresponse times (IRTs) less than $15 \mathrm{sec}$ are not reinforced and reset the interval. DRL was chosen because it is considered to be a difficult schedule, since it requires complete inhibition of responding for a period of time following the emission of a response.

Given the difficulty of maximizing the number of reinforced responses on DRL schedules, the conventional procedure for establishing DRL responding is to gradually increase the IRT requirement across sessions (Caplan \& Stamm, 1967; Farmer \& Schoenfeld, 1964; Harris, Farmer, \& Schoenfeld, 1966; Kelleher, Fry, \& Cook, 1959). Presumably, this procedure enables subjects to mediate long IRTs more successfully than if they had been placed directly on the terminal DRL schedule.

It has already been established that rats can rapidly

Order of authorship was determined by flip of coin. We thank Peter Ross and Albert Nerio, Jr., for their assistance. Reprints may be obtained from Laurence Miller, Department of Psychology, Western Washington University, Bellingham, Washington 98225 . acquire leverpressing with a CRF schedule, probably the simplest of reinforcement schedules to master. The present experiment examined whether rats could acquire DRL responding without assistance (e.g., shaping, magazine training, etc.). Three DRL schedules were examined: (1) DRL $7.5 \mathrm{sec}$, (2) DRL $15 \mathrm{sec}$, and (3) DRL 30 sec.

\section{METHOD}

\section{Subjects}

Twelve experimentally naive male albino rats, about 180 days old at the start of the experiment, were deprived to $80 \%$ of their free-feeding weight over a 7-day period prior to the start of the experiment.

\section{Apparatus}

Standard single-lever Grason-Stadler operant chambers were enclosed in sound-attenuating chests.

\section{Procedure}

When subjects reached $80 \%$ of their free-feeding weight, they were placed in the operant chamber for the first time, with DRL $7.5 \mathrm{sec}$ (Subjects 1-4), DRL $15 \mathrm{sec}$ (Subjects 5-8), or DRL 30 sec (Subjects 9-12) in effect. Fifteen daily sessions, each $40 \mathrm{~min}$ long, were presented. Because one animal (Subject 6) appeared to be acquiring the response only toward the 15 th session, additional sessions were presented.

\section{RESULTS}

The data are presented in Figures 1-3; a sample cumulative record from one animal in each condition is presented in Figure 4. All animals acquired and maintained the leverpressing response except for Subject 7. The data of Figures $1-3$ provide an index of changes in response efficiency over time. A direct relationship exists between the rate at which the responses and reinforcers converge and efficiency of responding. In order to directly compare the performance of the three groups, efficiency ratios for each group for the last five sessions were computed. This ratio 


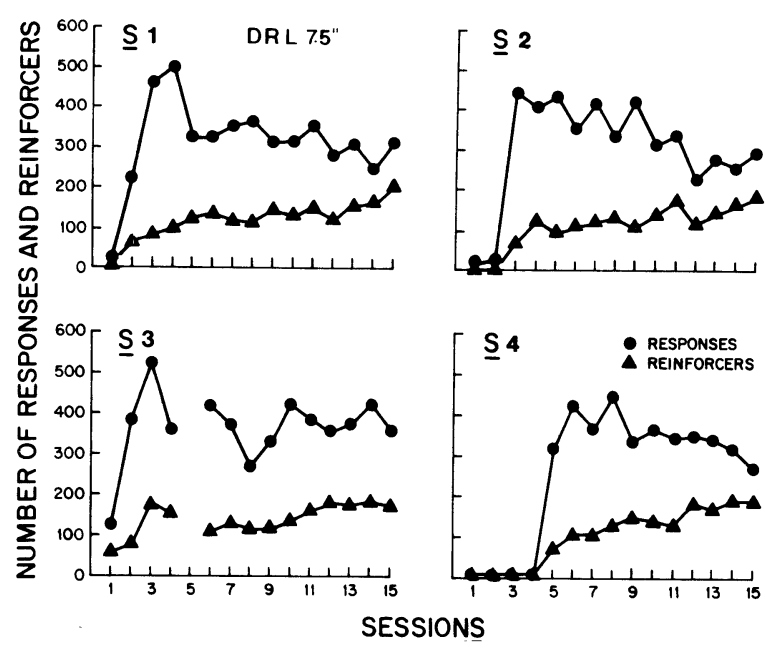

Figure 1. Number of responses and reinforcers during daily 40-min sessions on DRL 7.5 sec. Session 5 for Subject 3 was omitted due to malfunction of counters.

has been defined as the ratio between the number of reinforced responses and the total number of responses (Caplan, 1970). It varies from 0 to 1.0 , with 1.0 representing optimal response efficiencies. These ratios are presented in Table 1. A Type 1 ANOVA of these ratios revealed a schedules effect $[F(2,7)=19.1$, $p<.01]$. No other significant effects were found. A Newman-Keuls post hoc test revealed the efficency ratios of the DRL 30-sec group to be less than the DRL 15-sec group $(p<.02)$, which were in turn less than the efficiency ratios for the DRL 7.5-sec group $(\mathrm{p}<.05)$.

\section{DISCUSSION}

Eleven of 12 naive rats successfully acquired and maintained a leverpressing response reinforced according to different DRL schedules, without experimenter assistance. It appears that the

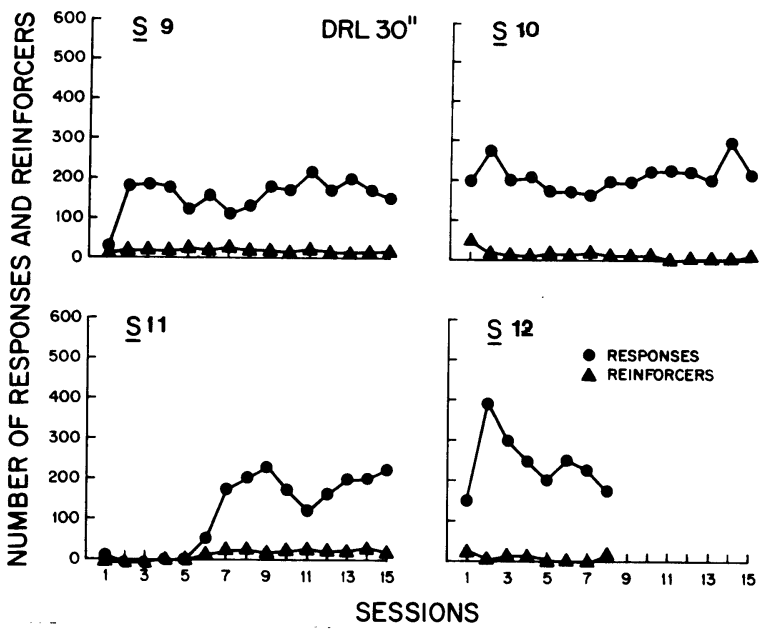

Figure 3. Number of responses and reinforcers during daily 40-min sessions on DRL 30 sec. Subject 12 became too ill to continue after Session 8.

pattern of responding is not different from that acquired with DRL schedules in the conventional manner: (1) As DRL value increased, efficiency of responding decreased. Kapostins (1963) found more accurate timing at lower DRL values, and Mallott and Cumming (1965) found that stable responding was acquired sooner with DRL schedules of short duration. (2) Bursting is evident. Bursts refer to sequences of very short responding. Bursts have been reported with short through long DRL values (Owens \& Brown, 1968; Sidman, 1956). Bursts in the present experiment are shown in the cumulative records.

The performance maintained by DRL $30 \mathrm{sec}$ is particularly interesting because substantial responding was maintained despite the infrequency of reinforcers. The mean efficiency ratio was less than .10; from 200 to 300 leverpresses typically occurred during a session, but only about 10 to 20 reinforcers were obtained. Performance might have become more efficient if training had been continued further. Relatively efficient performance can be maintained by DRL schedules with long values, but only if extended training is provided (Kelleher et al., 1959; Weiss, Laties, Siegel, \& Goldstein, 1966).

In summary, naive rats were found to be capable of acquiring
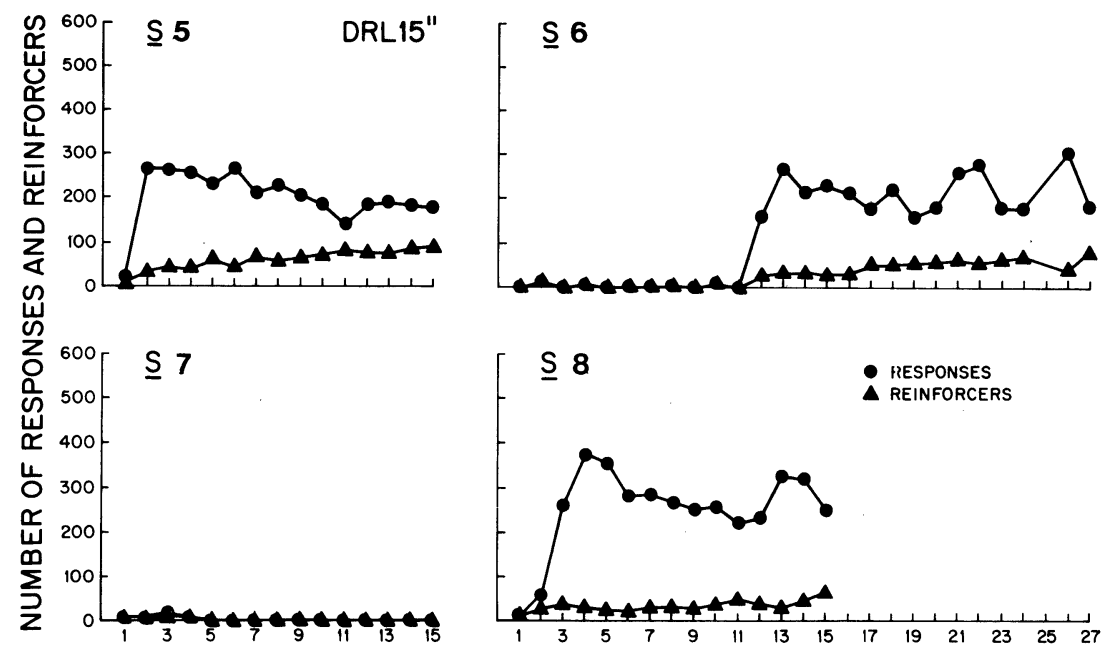

SESSIONS

Figure 2. Number of responses and reinforcers during daily 40-min sessions on DRL 15 sec. 


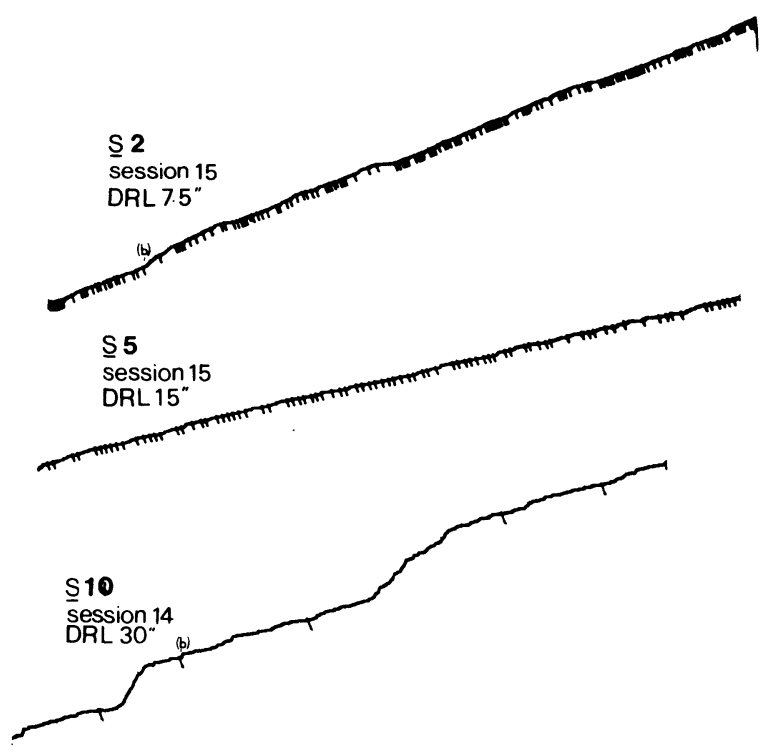

Figure 4. Sample cumulative record from each condition. Bursts are indicated by “(b)." Slash marks indicate delivery of reinforcers.

Table 1

Mean Efficiency Ratios for Last Five Sessions

\begin{tabular}{lrrrrrrr}
\hline & \multicolumn{5}{c}{ Session } & $\begin{array}{c}\text { Mean } \\
(1-5)\end{array}$ \\
\cline { 2 - 7 } & 1 & 2 & 3 & 4 & 5 & $(1-5)$ \\
\hline DRL 7.5 sec & .45 & .51 & .50 & .57 & .64 & .53 \\
DRL 15 & sec & .25 & .25 & .23 & .25 & .31 & .26 \\
DRL 30 & sec & .09 & .07 & .06 & .07 & .06 & .07 \\
\hline
\end{tabular}

leverpress responding on DRL schedules without experimenter assistance. Successful acquisition occurred with DRL values up to $30 \mathrm{sec}$. Sustained leverpressing frequently appeared quite early, often by the second session. Since rats are capable of rapidly acquiring leverpressing without assistance on simple (CRF) and complex (DRL) schedules, preliminary conditioning techniques such as magazine training and shaping may be unnecessary in most cases.

\section{REFERENCES}

Caplan, M. Effects of withheld reinforcement on timing behavior of rats with limbic lesions. Journal of Comparative and Physiological Psychology, 1970, 71, 119-135.

Caplan, M., \& Stamm, J. DRL acquisition in rats with septal lesions. Psychonomic Science, 1967, 8, 5-6.

FARMer, J., \& SChOENFELD, W. N. Interreinforcement times for the barpressing response of white rats on two DRL schedules. Journal of the Experimental Analysis of Behavior, 1964, 7, 119-122.

Harris, A. H., Farmer, J., \& Schoenfeld, W. N. Differentiation of response duration. Psychological Reports, 1966, 19. 619-625.

Kapostins, E. E. The effects of drl schedules on some characteristics of word utterance. Journal of the Experimental Analysis of Behavior, 1963, 6, 281-290.

Kelleher, R. T., FRY, W., \& CooK, L. Interresponse time distributions as a function of temporally spaced responses. Journal of the Experimental Analysis of Behavior, 1959, 2, 91-106.

Kopp, J., Bourland, G., Tarte, R. D., \& Vernon, C. R. Acquisition of bar pressing in nondeprived rats. Psychological Record, 1976, 26, 49-54.

Malott, R. W., \& Cumming, W. W. A note on multiple schedules of IRT reinforcement. Psychonomic Science, 1965, 2. 259-260.

Mille R, L. Acquisition of lever pressing by rats with and without magazine training. Psychological Record, 1976, 26, 355-359.

Owens, J. A., \& Brown, D. L. ICS reinforcement of DRL behavior in the rat. Psychonomic Science, 1968, 10, 309-310.

Sidman, M. Time discrimination and behavioral interaction in a free-operant situation. Journal of Comparative and Physiological Psychology, 1956, 49, 469-473.

Weiss, B., Laties, V., Siegel, L., \& Goldstein, D. A computer analysis of serial interactions in spaced responding. Journal of the Experimental Analysis of Behavior, 1966, 9.619-626.

(Received for publication May 30, 1978.) 